\title{
Correction to: Competition reduces profitability: the case of the Indian life microinsurance industry
}

\author{
Subrato Banerjee ${ }^{1,2,3} \cdot$ Basri Savitha $^{4}$ (D) \\ Published online: 5 February 2021 \\ (c) The Geneva Association 2021
}

\section{Correction to: The Geneva Papers on Risk and Insurance - Issues and Practice https://doi.org/10.1057/s41288-020-00203-5}

The original version of this paper was inadvertently published with an old e-mail address and an error in the affiliation of the author Subrato Banerjee.

The correct e-mail address is: subrato.banerjee@iitb.ac.in.

The correct affiliation is:

Assistant Professor, Indian Institute of Technology - Bombay

Behavioural Scientist, BEST Centre, Queensland University of Technology

Honorary Fellow, Australia India Institute, University of Melbourne.

The original article has been corrected. We apologise for any inconvenience caused to our readers.

Publisher's Note Springer Nature remains neutral with regard to jurisdictional claims in published maps and institutional affiliations.

The original article can be found online at https://doi.org/10.1057/s41288-020-00203-5.

\section{Basri Savitha}

bsbasri@gmail.com; savitha.bs@manipal.edu

Subrato Banerjee

subrato.banerjee@iitb.ac.in

1 Indian Institute of Technology - Bombay, Mumbai, India

2 BEST Centre, Queensland University of Technology, Brisbane, Australia

3 Australia India Institute, University of Melbourne, Parkville, Australia

4 Manipal Institute of Management, Centre for Advanced Research in Financial Inclusion,

Manipal Academy of Higher Education, Manipal, Karnataka 576104, India

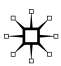

